\title{
CARACTERIZAÇÃO DA FRAÇÃO ARGILOSA DO SOLO SUPERFICIAL NA REGIÃO DA FUNDIÇÃO DE CHUMBO EM SANTO AMARO, BAHIA
}

\author{
L. R. P. DE ANDRADE LIMA* , R. C. SOUZA e L. A. BERNARDEZ \\ Universidade Federal da Bahia \\ lelo@ufba.br*
}

Artigo submetido em novembro/2013 e aceito em abril/2015

DOI: $10.15628 /$ holos.2015.1829

\section{RESUMO}

O solo da região da fundição primária de chumbo de Santo Amaro apresenta concentrações anômalas de $\mathrm{Pb}$ e $\mathrm{Zn}$ e outros elementos potencialmente nocivos como $\mathrm{Cu}, \mathrm{Cd}$ e As, devido às emissões atmosféricas da usina que operou por 33 anos. Visando compreender o processo de liberação-retenção destes elementos, assim como a definição de estratégias de descontaminacao este solo foi amostrado, tratado e caracterizado. Foi usada difração de raios- $X$, análise termo-gravimétrica, espectroscopia de infravermelho e refletância difusa da fração argila previamente separada e seca. Os resultados mostram que a fração argilosa deste vertissolo é composta por montmorilonita, ilita e caulinita. Devido ao fato destes argilo-minerais possuírem afinidade com vários cátions metálicos, a penetração dos elementos potencialmente tóxicos no solo da região da fundição primária de chumbo de Santo Amaro, é limitada apesar das altas concentrações verificadas na superfície.

PALAVRAS-CHAVE: solo contaminado; chumbo, zinco, metais pesados, argila.

\section{CHARACTERIZATION OF THE CLAY FRACTION OF THE TOP SOIL FROM THE SANTO AMARO LEAD SMELTER REGION, BAHIA}

\begin{abstract}
The soil of the region of the Santo Amaro lead smelter presents anomalous content of $\mathrm{Pb}$ and $\mathrm{Zn}$ and other potentially toxic elements such as $\mathrm{Cu}, \mathrm{Cd}$ and $\mathrm{As}$, due to the emissions from the smelter $t$. In order to understand the process of releasing-retention of these elements, as well as for the definition of remediation strategies, this soil was sampled, processed and characterized. In this study it was used X-ray diffraction, thermo-gravimetric analysis, infrared spectroscopy and diffuse reflectance
\end{abstract}

of clay fraction of this soil previously separated and dried. The results show that the clay fraction of this vertisol is composed of kaolinite, montmorillonite and illite. Due to the fact that these clay minerals have affinity with several metallic cations, the penetration of the potentially toxic elements in soil of the region of Santo Amaro lead smelter is low, despite of high concentrations at the top soil.

KEYWORDS: soil pollution; lead, zinc; heavy metals; clay 


\section{INTRODUÇÃO}

Em regiões próximas a usinas que produzem metais usando concentrados de minérios ricos em sulfetos metálicos e processos pirometalúrgicos o risco da contaminação do solo por elementos potencialmente tóxicos é uma séria fonte de preocupação. Estas usinas usam processos de oxidação que geram $\mathrm{SO}_{2}$ e material particulado, que se não for tratado adequadamente produzem emissões que estão fortemente associadas com a contaminação do solo (HARRISON e LAXEN, 1981; ALLOWAY, 1995; HABASHI, 2002). A avaliação das características químicas e mineralógicas dos solos nas proximidades destas usinas é importante para fornecer informações que possam ser usadas na proteção ou na definição de estratégias de tratamento dos solos contaminados.

Na cidade de Santo Amaro, Bahia uma fundição primaria de chumbo funcionou de 1960 a 1993. Vários estudos demonstraram a existência de contaminação por $\mathrm{Pb}$ e $\mathrm{Cd}$ na população de funcionários da empresa assim como em habitantes que viviam na proximidade desta usina (TAVARES et al., 1989; SILVANY-NETO et al., 1996). Estudos também demonstraram a existência de concentrações anômalas de elementos potencialmente tóxicos no solo da região próxima da usina (TAVARES, 1990; DE ANDRADE LIMA E BERNARDEZ, 2010; DE ANDRADE LIMA, 2013A, 2013B).

No município de Santo Amaro há uma formação geológica composta por folhelhos cinza esverdeados a pretos, silititos e arenitos lenticulares aflorantes (NASCIMENTO E TEIXEIRA, 1986). Esta formação apresenta vertissolos originários de folhelhos esverdeados, intercalados com calcários argilosos a muito argilosos, com predominância de argilas do grupo da montmorilonita. A zona de vertissolos nesta região tem uma forma alongada, predominando a direção Norte/Sul, com cerca de $70 \mathrm{~km}$ de extensão e $10 \mathrm{~km}$ de largura (NASCIMENTO E TEIXEIRA, 1986). Este tipo de solo é encontrado em toda área da fundição de chumbo de Santo Amaro.

Argilo-minerais encontrados em vertissolos possuem afinidade com cátions metálicos que interagem com a superfície ou com o espaço entre as lamelas. A afinidade da montmorilonita pode ser ordenada com: $\mathrm{Pb}>\mathrm{Cu}>\mathrm{Cd}>\mathrm{Zn}$, enquanto a afinidade da ilita e da caulinita pode ser ordenada: $\mathrm{Pb}>\mathrm{Cu}>\mathrm{Zn}>\mathrm{Cd}$ ) (ALLOWAY, 1995).

Neste trabalho a fração argilosa da camada superficial do solo coletado próximo da fundição de Santo Amaro foi isolada e usada para uma caracterização química e mineralógica, visando dar subsídios para a definição de rotas para o tratamento deste solo.

\section{METERIAS E MÉTODOS}

\subsection{Localização do sitio}

A região estudada esta localizada nas imediações da cidade de Santo Amaro, que encontra-se no Recôncavo baiano, a $72 \mathrm{~km}$ a Noroeste da cidade de Salvador (Figura 1a). Santo Amaro tem uma população de cerca de 61,5 mil habitantes e sua economia esta fortemente associada à agricultura. Nesta região encontra-se a estrutura remanescente da fundição de chumbo desativada desde 1993 (Figura 1b) (TAVARES, 1990; DE ANDRADE LIMA E BERNARDEZ, 2010; DE ANDRADE LIMA, 2013A, 2013B). 


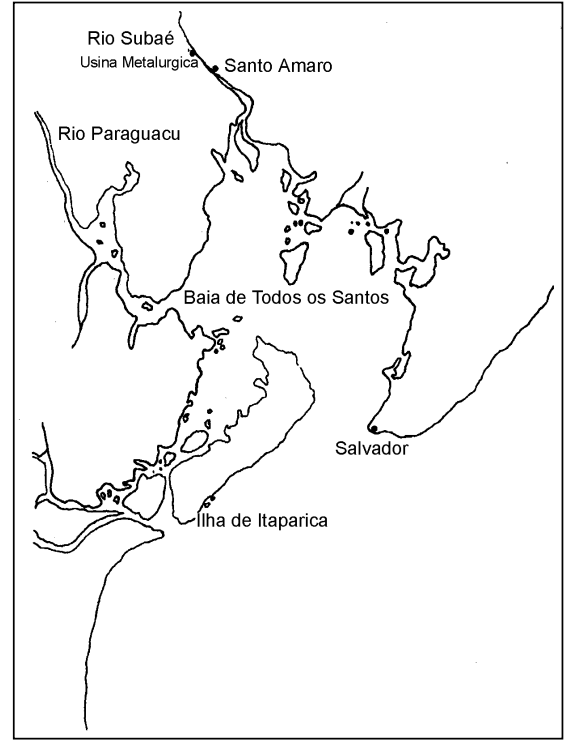

(a)

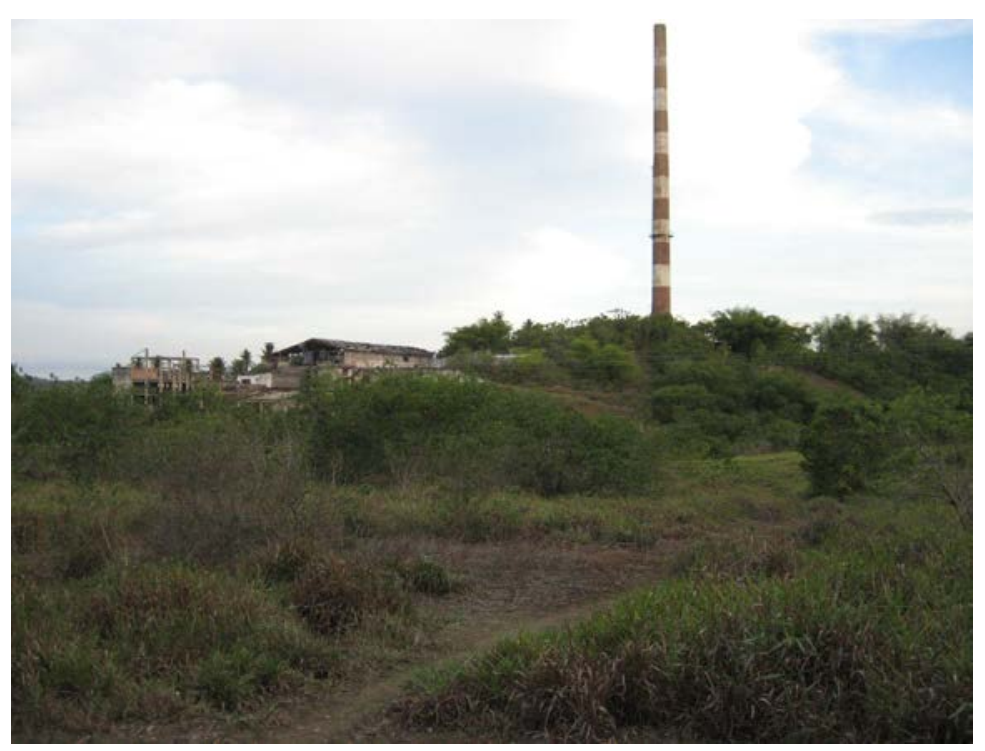

(b)

Figura 1 - a) Localização do sítio estudado e b) foto da fundição de chumbo de Santo Amaro.

\subsection{Analise química do solo in-situ}

Para a analise in-situ do solo localizado próximo da fundição (Figura 2), a vegetação superficial foi removida e o analisador portátil de fluorescência de raios X, NITON XL3 t 500, com a calibração de solos, foi usado. Procedimento análogo foi usado e um corte lateral do terreno localizado próximo da fundição a fim de permitir a identificação do perfil de concentrações de elementos potencialmente tóxicos.

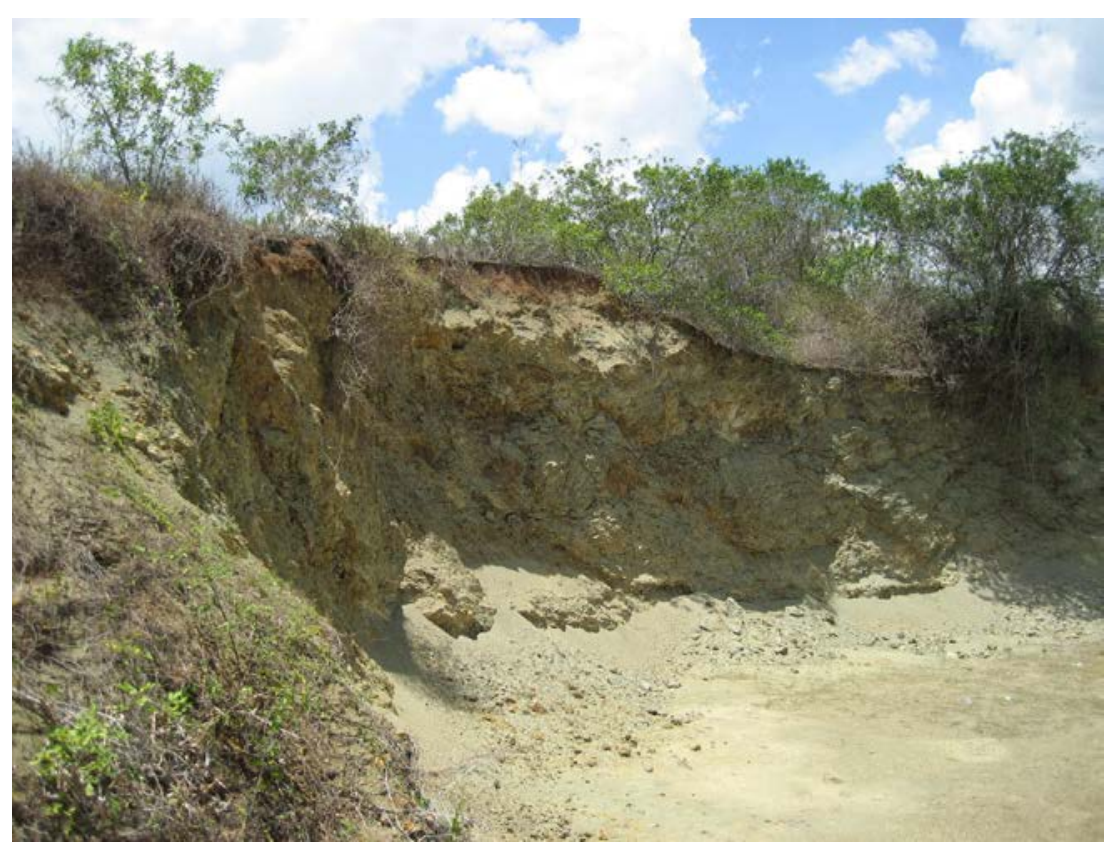

Figura 2 - Localização do sítio estudado 


\subsection{Amostragem do solo}

A vegetação rasteira foi removida e uma camada de cerca de $20 \mathrm{~cm}$ do solo foi retirada em vários pontos na área externa à fundição de chumbo de Santo Amaro, em uma região que não sofreu movimentação de terreno. O solo coletado foi colocado em bandejas e deixado secar em um ambiente com umidade relativa de cerca de $55 \%$ e temperatura de $21^{\circ} \mathrm{C}$.

\subsection{Extração da fração argilosa do solo}

Para identificação dos argilo-minerais contidos no solo as amostras foram tratadas com as seguintes etapas (sumarizadas na Figura 3):

i) Remoção total de matéria orgânica: utilizou-se um erlenmeyer de $500 \mathrm{~mL}$ contendo $200 \mathrm{~g}$ de solo seco ao ar nos quais foram adicionados $250 \mathrm{~mL}$ de água destilada, mantendo sob agitação durante 10 minutos e posteriormente foram adicionados $10 \mathrm{~mL}$ de peróxido de hidrogênio $\left(\mathrm{H}_{2} \mathrm{O}_{2}\right) 30$ volumes. A solução restante foi aquecida em banho-maria a $40^{\circ} \mathrm{C}$ por um período de 24 horas.

ii) Remoção do ferro livre: adicionou-se $50 \mathrm{~mL}$ de uma solução de citrato de sódio $\left(\mathrm{C}_{3} \mathrm{H}_{4} \mathrm{OH}(\mathrm{COOH})_{2} \mathrm{COONa}\right)$ e elevou-se a temperatura do banho-maria para $75^{\circ} \mathrm{C}$. Após atingir esta temperatura adicionou-se $1,0 \mathrm{~g}$ de ditionito de sódio $\left(\mathrm{Na}_{2} \mathrm{~S}_{2} \mathrm{O}_{4}\right)$, por duas vezes até o material ficar claro, evidenciando a eliminação do ferro.

iii) Floculação: a suspensão foi mantida em repouso por 2 horas para facilitar a floculação. Posteriormente o material foi centrifugado com remoção do líquido sobrenadante. Após este processo retirou-se $60 \mathrm{~g}$ da amostra que foi transferida para uma proveta de $1000 \mathrm{~mL}$. Nesta foi adicionada uma solução de cloreto de sódio $(\mathrm{NaCl})$ com concentração $2,0 \mathrm{~g} / \mathrm{L}$. A suspensão foi mantida em repouso durante 24 horas e posteriormente $\mathrm{o} \mathrm{pH}$ foi ajustado para 9,5 com $\mathrm{NaOH} \mathrm{0,1}$ $\mathrm{mol} / \mathrm{L}$, visando facilitar a floculação.

iv) Separação da fração fina: ao longo de duas semanas o líquido sobrenadante na suspensão de argila foi trocado a cada 24 horas e foi adicionada uma solução de $\mathrm{NaCl}$ com concentração de $2,0 \mathrm{~g} / \mathrm{L}$ seguida de agitação visando a dispersão em uma proveta com um bastão de vidro. Sabendo que no fracionamento da suspensão de argila foi extraído apenas os $20 \mathrm{~cm}$ superior da proveta, as frações recolhidas têm o tamanho médio estimado, através da lei de Stokes, como inferior a 2,0 $\mu \mathrm{m}$. Findada esta etapa, realizou-se o processo de lavagem contínua do material com água destilada, por centrifugação a 800 RPM. A repetição do processo teve o objetivo de reduzir a condutividade de $100 \mu \mathrm{S}$ para um valor inferior a $30 \mu \mathrm{S}$, indicando expressiva eliminação de íons dissolvidos. Para garantir a retirada do excesso de íons cloreto foram retiradas alíquotas de $1,0 \mathrm{~mL}$ da solução e após a adição de uma solução de nitrato de prata $\left(\mathrm{AgNO}_{3}\right)$ a 0,1 mol/L foi verificada o surgimento de turbidez devido a formação de cloreto de prata. 


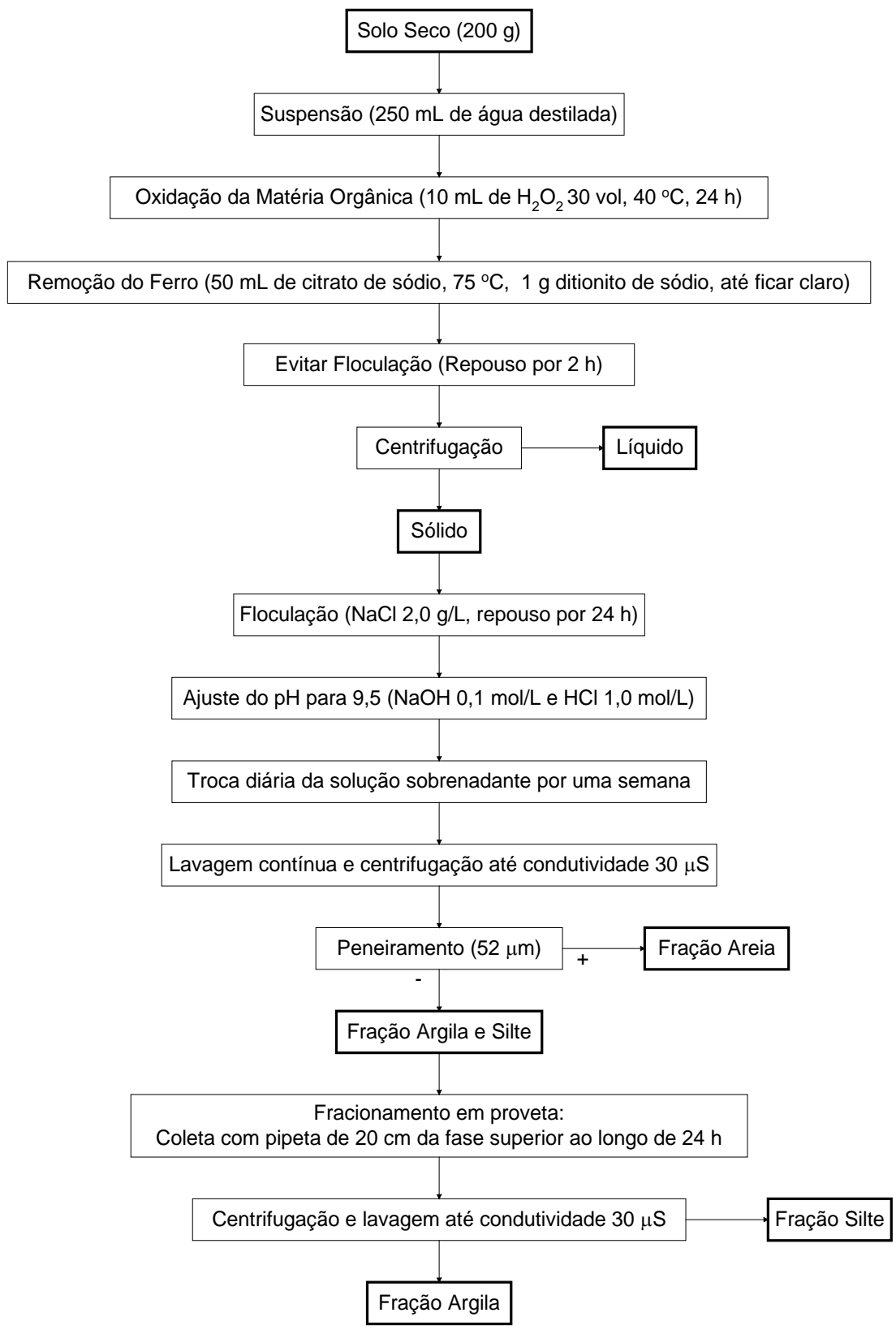

Figura 3 - Fluxograma do fracionamento do solo

\subsection{Analise química e mineralógica do solo}

Após secagem as amostras da fração argila foram caracterizadas através de: i) difração de raios $X$ com o difratômetro Siemens modelo $D-5000$, ii) espectroscopia de plasma opticamente acoplado (ICP-OES) usando o ICP Fisions ARL-Instruments modelo 3410, iii) análise termogravimétrica (TD) usando o Shimadzu modelo TG-50, iv) espectroscopia infra-vermelho com transformada de Fourier (FTIR) usando o Jasco modelo valor III, v) espectroscopia UV-Vis no modo reflectância difusa (DRS) usando o Varian modelo CARY-5 e microscopia eletrônica de varredura usando o MEV Philips modelo XL30 (NUCAT, COPPE, UFRJ). 


\section{RESULTADOS E DISCUSSÃO}

A Figura 4 mostra os perfis de concentração de $\mathrm{Pb}, \mathrm{Zn}, \mathrm{Cu}$ e As no solo próximo à usina, que foram medido in-situ. observa-se que a superfície do solo tem concentrações elevadas, que são reduzidas à medida que ocorre a o aprofundamento no solo, indicando a afinidade dos elementos com o solo, o que indica que o uso de métodos de descontaminação envolvendo solubilização podem apresentar re-adsorção destes elementos.

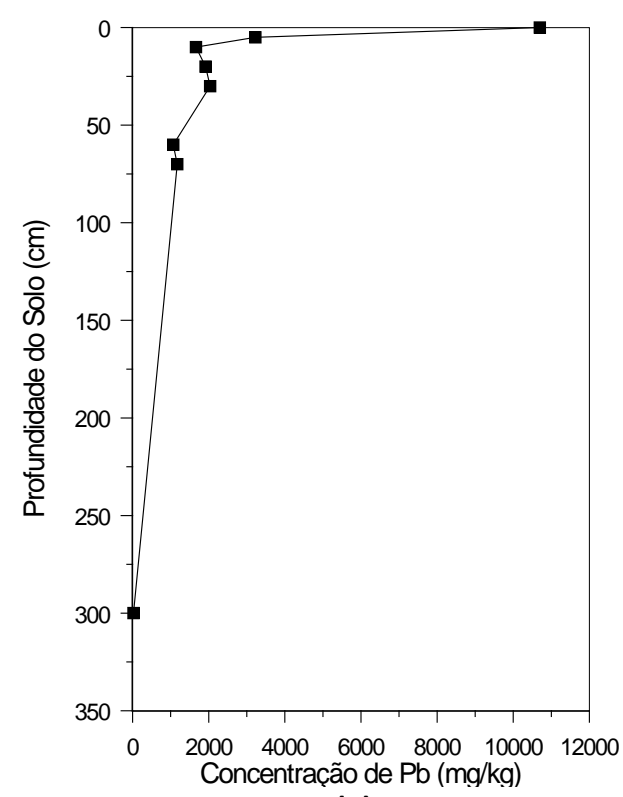

(a)

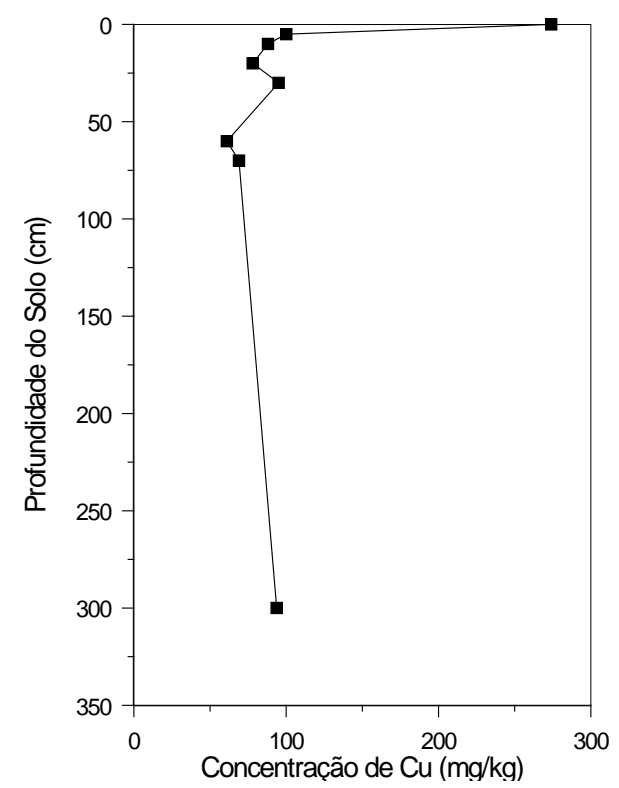

(c)

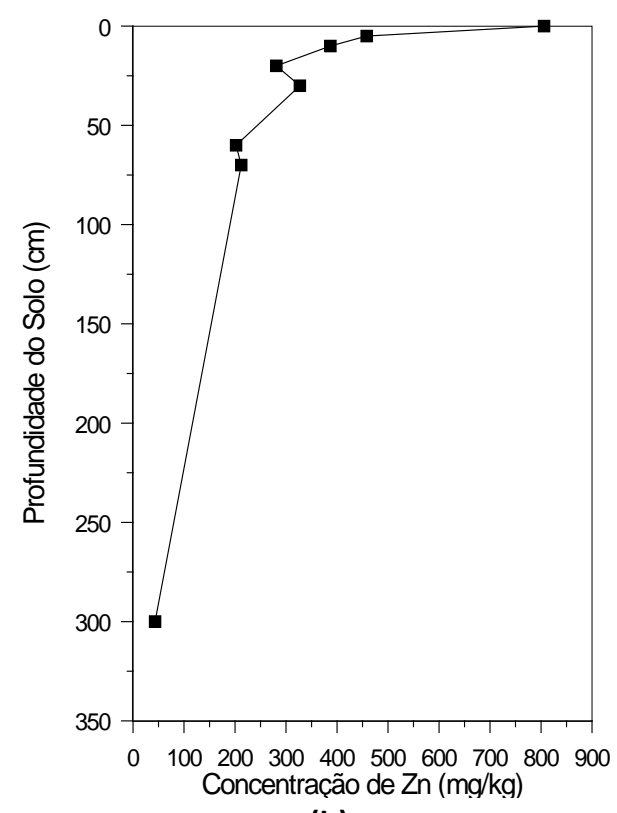

(b)

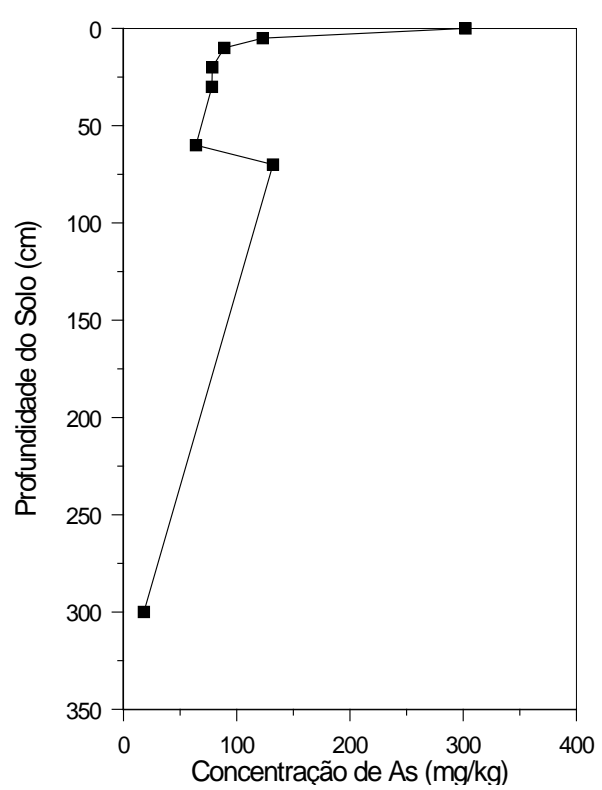

(d)

Figura 4 - Perfis de concentração de: a) Pb, b) Zn, c) Cu e d) As no solo

A Figura 5 mostra uma imagem da fração argilosa do solo (separada de acordo com o esquema mostrado na Figura 3) feita no microscópio eletrônico de varredura, em elétrons secundários. Nota-se que esta fração é composta essencialmente de agregados de cristalitos em placa, cujo tamanho apresenta significativa variação. 


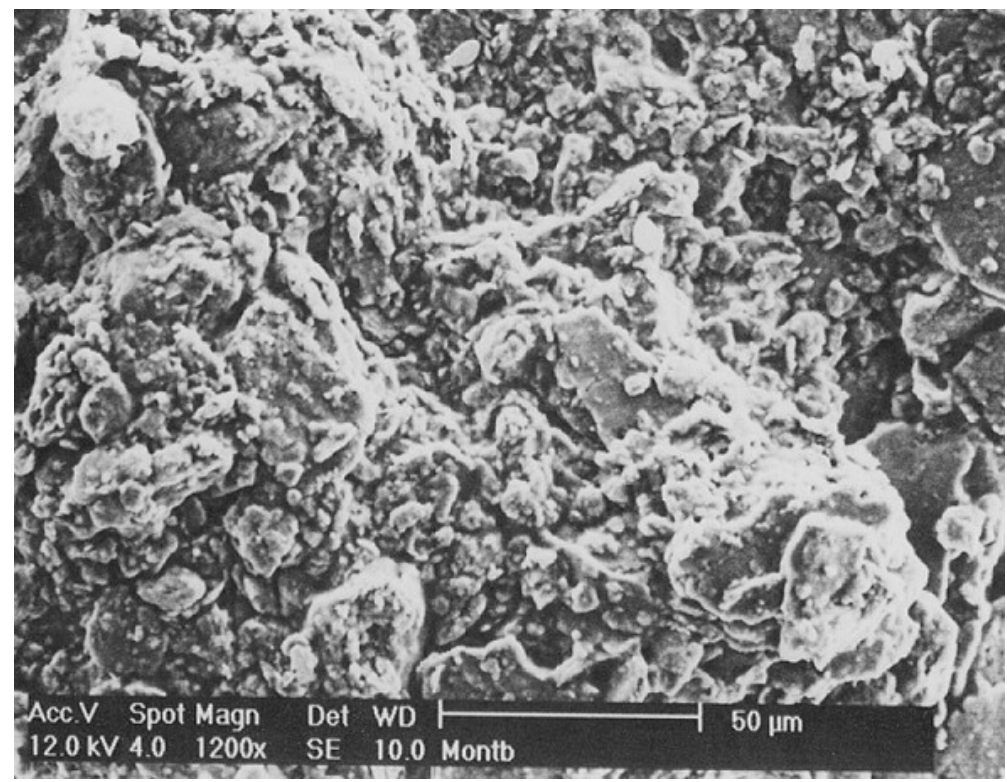

Figura 5 - Micrografia em elétrons secundários de uma amostra da fração argila concentrada do solo.

A difração de raios $X$ da fração argilosa, mostrada na Figura 6, mostra a presença de montmorilonita $(\mathrm{Na}, \mathrm{Ca})_{0.33}(\mathrm{Al}, \mathrm{Mg})_{2}\left(\mathrm{Si}_{4} \mathrm{O}_{10}\right)(\mathrm{OH})_{2} \cdot \mathrm{nH}_{2} \mathrm{O}$, mas mostra a presença de ilita $\left(\mathrm{K}, \mathrm{H}_{3} \mathrm{O}\right)(\mathrm{Al}, \mathrm{Mg}, \mathrm{Fe})_{2}(\mathrm{Si}, \mathrm{Al})_{4} \mathrm{O}_{10}\left[(\mathrm{OH})_{2},\left(\mathrm{H}_{2} \mathrm{O}\right)\right]$ e de caulinita, $\mathrm{Al}_{2} \mathrm{Si}_{2} \mathrm{O}_{5}(\mathrm{OH})_{4}$. A montmorilonita é formada por uma unidade de gibsita $\left(\gamma-\mathrm{Al}(\mathrm{OH})_{3}\right)$ entre duas de sílica $\left(\mathrm{SiO}_{2}\right)$ superpostas e a interação entre duas camadas de sílica é fraca, permitindo a penetração de moléculas de água, o que provoca apreciável variação volumétrica, assim como de cátions metálicos (GRIM E KULBICKI, 1961).

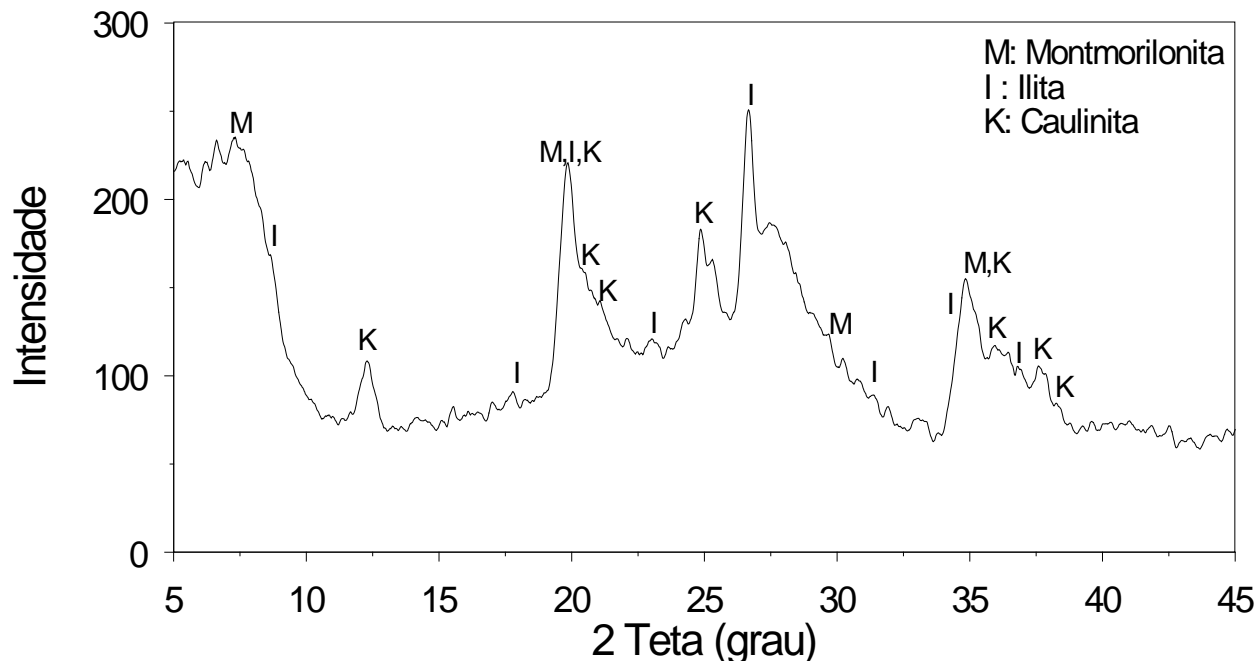

Figura 6 - Difratograma de raios $\mathrm{X}$ do concentrado de argila.

O resultado da análise química de alguns elementos na argila é mostrado na Tabela 1. Como a montmorilonita é basicamente composta de alumínio e magnésio na estrutura do silicato hidratado, o elevado teor de ferro na argila pode ser explicado pela significativa concentração de ilita. 
Tabela 1 - Concentração dos maiores elementos na fração argila (em \%)

\begin{tabular}{cc}
\hline $\mathrm{Al}_{2} \mathrm{O}_{3}$ & 22,3 \\
$\mathrm{Fe}_{2} \mathrm{O}_{3}$ & 10,7 \\
$\mathrm{Na}_{2} \mathrm{O}$ & 0,3 \\
\hline
\end{tabular}

A análise termogravimétrica da fração argilosa, Figura 7, revela a presença de quatro regiões de perda de massa, sendo as três primeiras as mais relevantes. A primeira região até cerca de $100^{\circ} \mathrm{C}$ referente à perda de água superficial. A segunda região, entre 100 e $300^{\circ} \mathrm{C}$ referese à perda de água interlamelar. A terceira perda de massa, entre 300 e $600^{\circ} \mathrm{C}$ ocorre devido à perda das hidroxilas dos retículos cristalinos, tanto para a ilita, quanto para a caulinita e sobretudo para a montmorilonita, com o colapso das estruturas (GRIM e KULBICKI, 1961).

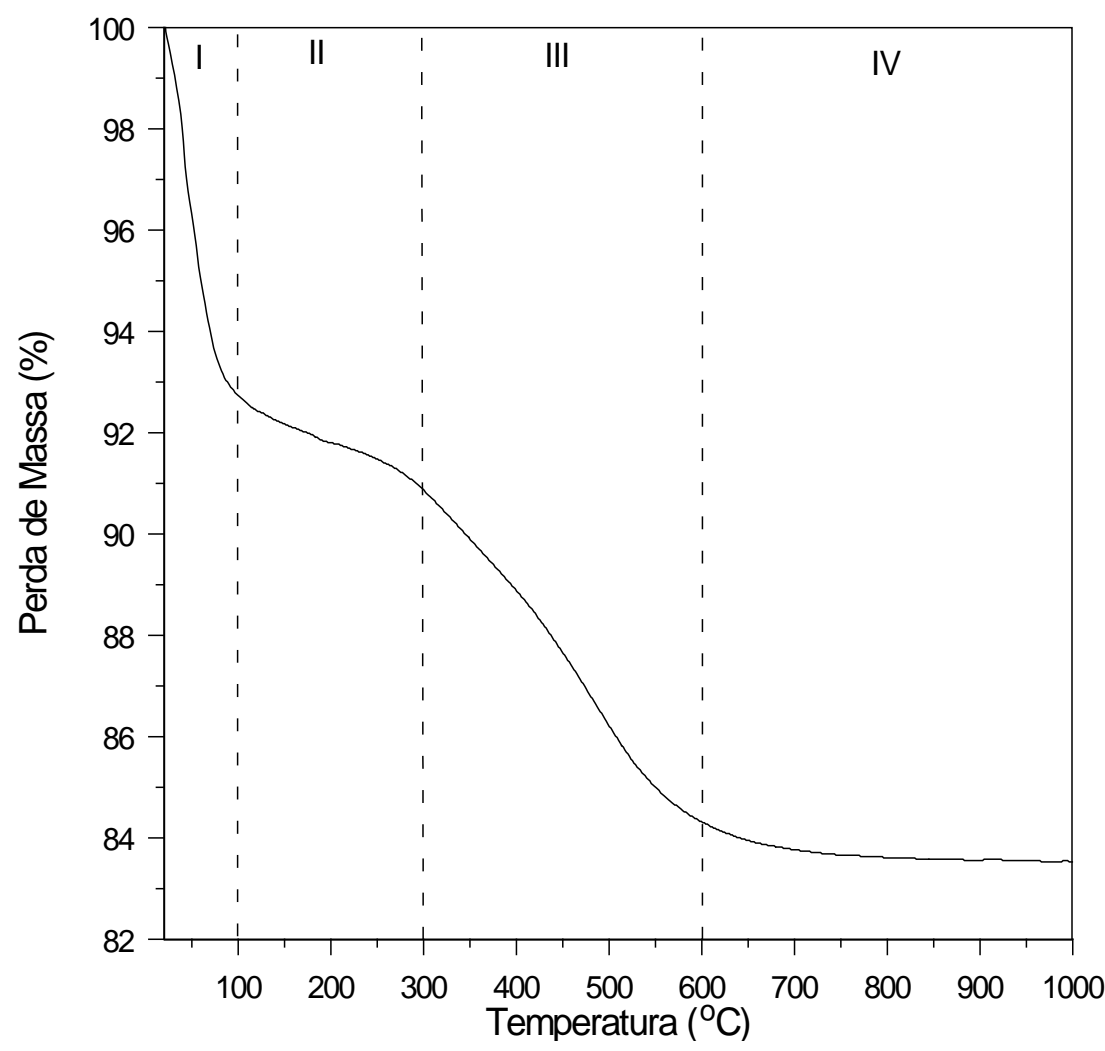

Figura 7 - Curva termogravimétrica do concentrado de argila.

As Figuras 8a e 8b mostram o espectro de infravermelho da fração argilosa para as regiões de comprimento de onda média e longa, nos quais é possível identificar as bandas na região de $3800-3000 \mathrm{~cm}^{-1}$ que correspondem ao estiramento dos diversos grupos $\mathrm{OH}$ - presentes nos minerais, seja devido a grupos $\mathrm{SiOH}$ (silanóis), hidroxilas em ponte ( $\mathrm{Si}-\mathrm{OH}-\mathrm{Al}, \mathrm{Si}-\mathrm{OH}-\mathrm{Mg}$ ou $\mathrm{Si}-$ $\mathrm{OH}-\mathrm{Fe}$ ), mas também devido à água de hidratação interlamelar. A banda em $1634 \mathrm{~cm}^{-1}$ se deve à deformação angular das ligações $\mathrm{H}-\mathrm{O}-\mathrm{H}$ das moléculas de água interlamelar. É possível identificar bandas em 3690 e $3649 \mathrm{~cm}^{-1}$, que são atribuídas ao acoplamento em fase e fora de fase das vibrações $\mathrm{O}-\mathrm{H}$ entre as folhas octaédrica e tetraédrica. 


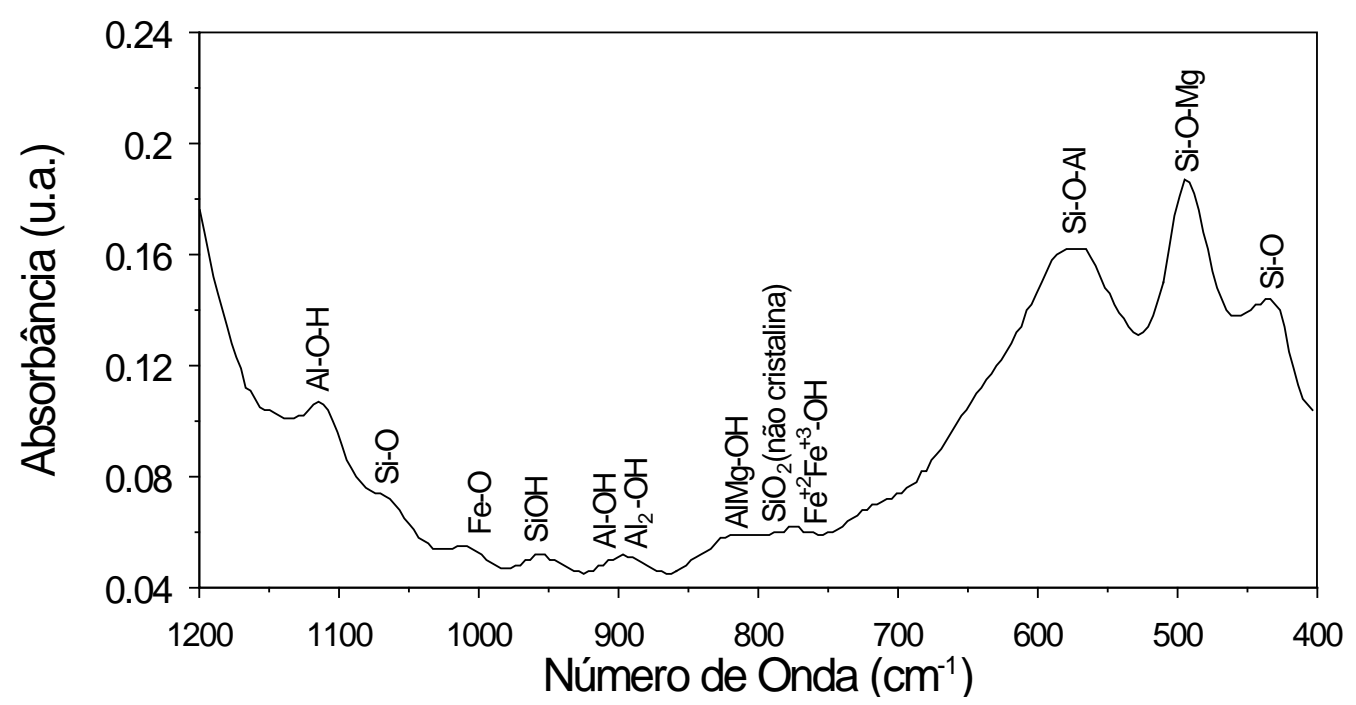

(a)

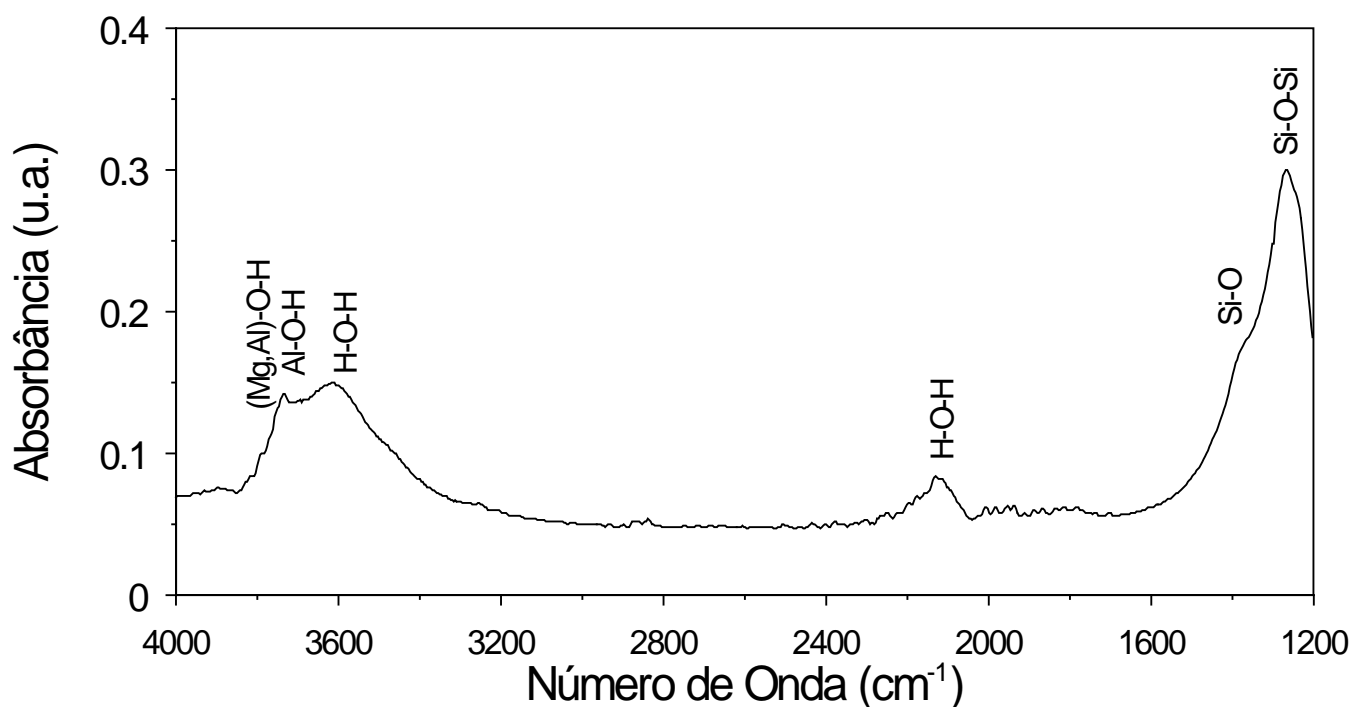

(b)

Figura 8 - Espectros de infravermelho do concentrado de argila. a) Radiação infravermelha longa e b) Radiação infravermelha média.

A análise por espectrometria UV-Vis no modo reflectância difusa (DRS) é mostrada na Figura 9. Neste método espectroscópico a região entre 800 e $2500 \mathrm{~nm}$ de infravermelho próxima do visível que é a mais energética é usada visando encontrar harmônicos (sobretons) ou bandas de combinação referentes às ligações químicas das moléculas. Na Figura 9 nota-se que o sobretom referente a vibração de estiramento do $\mathrm{OH}$ - estrutural que é encontrado em torno de $1389 \mathrm{~nm}$. Nota-se a presença do sobretom para a vibração de estiramento do $\mathrm{OH}$ das moléculas de água (que normalmente ocorre a 1408 e $1461 \mathrm{~nm}$ ) sugerindo a existência de dois tipos de água. A banda de combinação $v+\delta$ da água ocorre a $1900 \mathrm{~nm}$ enquanto esta banda para os $\mathrm{OHs}$ estruturais ocorrem em três bandas, 2210, 2318 e 2388 nm, que dependem do ambiente dos grupos $\mathrm{OH}$ (CHE et al., 2011). 


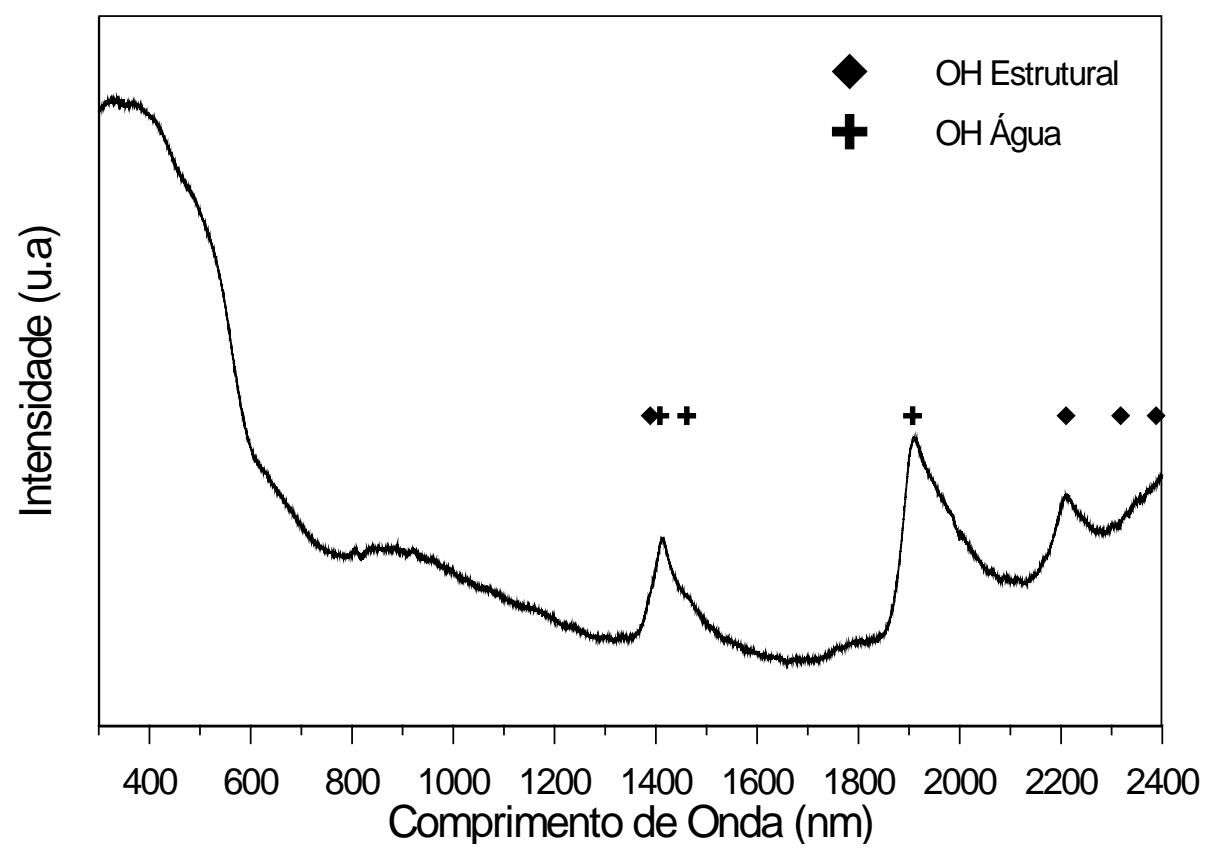

Figura 9 - Espectro de reflectância difusa do concentrado de argila.

\section{CONCLUSÕES}

O solo da região da fundição primária de chumbo de Santo Amaro, Bahia, foi amostrado, tratado e analisado. Os resultados mostram que a fração argilosa deste vertissolo é composta por montmorilonita, ilita e caulinita. Estes argilo-minerais possuem afinidade com cátions metálicos o que explica, em parte, a longa retenção e a difícil penetração dos elementos potencialmente tóxicos no solo da região da fundição de Santo Amaro, apesar do longo tempo da deposição (de 1960 a 1993) e das altas concentrações verificadas na superfície do solo. Estes resultados mostram que o uso de métodos de descontaminação dos elementos potencialmente tóxicos envolvendo mobilização-solubilização podem apresentar sérias dificuldades, devido a possível readsorção destes elementos nos argilo-minerais.

\section{AGRADECIMENTOS}

Os autores agradecem o apoio financeiro para este estudo do Conselho Nacional de Desenvolvimento Científico e Tecnológico (CNPq) através do processo n. 484094/2011-4. L. A. Bernardez é bolsista do Programa Nacional de Pós-Doutorado (CAPES/PNPD) junto ao Programa de Pós-Graduação de Engenharia Industrial da Universidade Federal da Bahia.

\section{REFERÊNCIAS BIBLIOGRÁFICAS}

1. ALLOWAY, B. J. Heavy Metals in Soils, Chapman \& Hall, Glasgow, 1995.

2. CHE, C., GLOTCH, T.D., BISH, D.L., MICHALSKI, J.R., XU, W. Spectroscopic study of the dehydration and/or dehydroxylation of phyllosilicate and zeolite minerals. J. Geohys. Res., v. 116, p.E05007, 2011. 
3. DE ANDRADE LIMA, L.R.P., BERNARDEZ, L.A. Characterization of the heavy metals contamination due to a lead smelting in Bahia, Brazil. In: Lead-Zinc 2010. SIEGMUND, A., CENTOMO, L., GEENEN, C., PIRET, N., RICHARDS, G., STEPHENS, R. (editors), Wiley - The Minerals, Metals \& Materials Society, p.917-927, 2010.

4. DE ANDRADE LIMA, L.R.P. Letter to the editor regarding: a study of the routes of contamination by lead and cadmium in Santo Amaro, Brazil. Environmental Technology, v.34, p.2903-2904, 2013.

5. DE ANDRADE LIMA, L.R.P. Rebuttal to authors' response regarding 'A study of the routes of contamination by lead and cadmium in Santo Amaro, Brazil', Environmental Technology, v.34, p.2909-2915, 2013

6. GRIM, R.E., KULBICKI, G. Montmorillonite: High temperature reactions and classification. Am. Mineral., v.46, p.1329-1369, 1961.

7. HABASHI, F., Textbook of pyrometallurgy, Canada: Métallurgie Extractive Québec, 2002.

8. HARRISON, R.M, Laxen D.P.H. Lead pollution: causes and control. London: Chapman and Hall, $168 p ; 1981$.

9. NASCIMENTO, A.M., TEIXEIRA, L.R. Mapa Pedoquímico do Estado da Bahia: Texto Explicativo, Superintendência de Geologia e Recursos Minerais, Bahia, 81p., 1986.

10. SILVANY-NETO, A.M., CARVALHO, F.M., TAVARES, T.M., GUIMARÃES, G.C., AMORIM, C.J.B., PERES, M.F.T. Lead poisoning among children from Santo Amaro, Bahia, Brazil in 1980, 1985, and 1992. Bull. Pan Am. Health Organ., v.30, p.51-62, 1996.

11. TAVARES, T.M., BRANDÃO, A.M., CARVALHO CHAVES, M.E., SILVANY NETO, A.M., CARVALHO F.M. Lead in hair of children exposed to gross environmental pollution. Int. J. Environ. Anal. Chem., v. 36, p.221-230, 1989.

12. TAVARES, T. M. Avaliação de efeitos das emissões de cádmio e chumbo em Santo Amaro, Bahia, Tese de Doutorado em Química, Universidade de São Paulo, 1990. 